\title{
Students' Perceptions on Participating in Remote Learning Activities in the Time of COVID-19 Pandemic
}

\author{
${ }^{*}$ F M Nawastheen ${ }^{1}$, S.A.S. K Perera ${ }^{1}$ \\ ${ }^{1}$ Department of Secondary and Tertiary Education, Faculty of Education, The Open University of Sri Lanka, Sri \\ Lanka
}

\begin{tabular}{l} 
Article Info \\
\hline Article history: \\
Received September 26, 2021 \\
Revised November 17, 2021 \\
Accepted November 18, 2021 \\
Available Online December 30, 2021 \\
\hline
\end{tabular}

Keywords:

COVID-19

Remote Learning Activities (RLA)

Perceptions

School students

Sri Lanka

\begin{abstract}
The present study aimed to assess Sri Lankan school students' perceptions of the experience of participating in remote learning activities (RLA) available to them during the time of the COVID-19 pandemic. This study was conducted as a survey. Using the exponential non-discriminative snowball sampling technique, data were collected from 613 school students through a questionnaire administered as a Google Form. Data were analyzed as mean values, standard deviations, and percentages. Analysis of data revealed that majority of respondents $(92 \%)$ were well aware of the various RLA. The majority of the respondents $(62.6 \%)$ used mobile internet and $69.5 \%$ used prepaid services. The main challenges they faced were related to affordability, the heavy load of educational content presented through RLA, and concerns on cyber security when engaging with RLA. To make opportunities for learning more accessible to learners, it is recommended that mobile data be made available to school students at low costs and all educational programs should be made available to them free of charge. In addition, devices such as tablets should be provided to all students to ensure equality of access to education. Further, studies on parents' and teachers' experiences with their children's and students' learning through RLA would complement the findings of this study.
\end{abstract}

\section{INTRODUCTION}

After the WHO declared COVID-19 as a global pandemic in early March 2020, around 107 countries took steps to close their schools to maintain physical distancing among the students to mitigate the spread of the disease (Viner et al., 2020). However, as of May 2020, this situation had severely affected the formal education of 1,186 million students from 144 countries. The DirectorGeneral of UNESCO opined that more than 1.5 billion students across the planet were affected by the closing down of schools and universities due to the COVID-19 outbreak. This situation could be viewed as a threat to the rights to education (UNESCO, 2020). School, as a principal formal educational institution, provides learning spaces for students under the guidance of teachers. Conventionally, teachers play the crucial role of facilitating student learning through face-to-face sessions. As a result of the pandemic, the traditional approach to teaching and learning in schools collapsed. Though many countries stumbled initially, they quickly realized the gravity of the situation and adopted alternatives for school teaching-learning activities with the help of educational technology. World Bank Group (2020) and UNESCO (2020) have documented how, during this period, various countries have been using educational technology to reach out to students through remote learning.

The term 'remote learning' refers to learning where the student and the teacher (or the information source) are not physically present in a traditional classroom environment (Top Hat, 
2020). It particularly refers to teachers' and learners' engagement in teaching-learning activities in the absence of physical meetings. It is similar to the concept of 'distance learning' to a considerable extent but is distinguished as occurring when the learner and the teacher (or the source of information) are separated by time and distance thus hindering their meeting in a traditional face-to-face classroom context. On the other hand, distance learning refers to a way of learning remotely without having regular face-to-face contact with the teacher in a traditional classroom setting (Sears, 2020). Since schools around the globe were closely followed by the declaration of COVID-19 as a pandemic, there has been an increasing trend in offering remote learning activities (RLA) to compensate for the closure of schools.

In the Sri Lankan context, various internet-based and non-internet-based RLA are being carried out by governmental and non-governmental entities to facilitate school students' learning during the COVID-19 pandemic. With the sudden closure of schools in Sri Lanka, students who were preparing for Grade 5 Scholarship Examination, G.C.E. Ordinary Level (G.C.E. O/L) Examination, and G.C.E. Advanced Level (G.C.E. A/L) Examination was deeply concerned about the continuation of their formal studies. Ministry of Education, in collaboration with the National Institute of Education, took gradual steps to address the concerns of students and their parents. Consequently, two educational programs, namely Gurugedera (Sinhala) and Gurukulam (Tamil) were initiated with the partnership of Rupavahini, the state-owned television network. Accordingly, Channel Eye and Nethra TV, television channels of Rupavahini, initiated the broadcast of educational content during the time of the closure of schools. Likewise, E-thaksalava, the national e-learning portal of the Ministry of Education, offered learning materials to facilitate the learning of grade one to twelve students in the safety of their homes (UNESCO, 2020).

In addition, state-owned radio channels and local private TV channels also allocated considerable amounts of time to broadcast educational programs which aimed to cover school lessons, especially for Grade 5 and G.C.E. A/L students. In addition, other stakeholders, i.e. Zonal Offices of Education, private schools, other educational institutions, and volunteers have initiated online teaching using social media (e.g. - through Zoom meetings, Google and Microsoft meetings, Facebook live, and WhatsApp groups). These RLA mostly rely on the internet and modern electronic devices such as smartphones, tablets, and computers for the delivery of educational content and activities. This has resulted in an abrupt upsurge in internet usage in the country, where $60 \%$ of households with school-aged children have no access to the internet (Ranawana, 2020). Against this backdrop, it would be of interest to study Sri Lankan school students 'perceptions of their experience of participating in RLA at their disposal. For achieving the main aim of the study, the following research questions were addressed:

1. To what extent are Sri Lankan school students aware of opportunities available for them to engage in RLA?

2. What are the facilities available for the students to engage in RLA at home?

3. What are the students' perceptions of remote learning?

4. What are the challenges and issues faced by the students when engaging in remote learning?

\section{LITERATURE REVIEW}

Several studies have been conducted on children's remote learning in the aftermath of the COVID-19 pandemic. In their survey, Zainudeen and Amarasinghe (2020) revealed that $66 \%$ of Sri Lankan households with school-aged children had no access to internet, and only $48 \%$ of households with school-aged children had a smartphone or computer. This means that dissemination of RLA through the internet could reach only $34 \%$ of the households. Further, it was revealed that the majority $(78 \%)$ of households have mobile phones while $12 \%$ of the households have a computer or laptop. Still, around $52 \%$ of households with children (aged less than 18) do not have a smartphone or computer in their homes (Zainudeen \& Amarasinghe, 2020). However, this rate of access to internet at the household level of school-aged children in Sri Lanka (i.e. 34\%) is higher than that of other South Asian countries, with India having an access rate of 
$20 \%$, Pakistan $8 \%$, and Bangladesh $11 \%$. Nonetheless, the affordability of data is a major obstacle to internet access among low-income earners in the country (Zainudeen \& Amarasinghe, 2020). According to the Department of Census and Statistics (2019), one out of every five households in Sri Lanka owns either a desktop or a laptop computer. But due to the changing trend of moving from the use of a computer to smartphones/tablets, digital literacy is continuously increasing among people in the country. In 2019, the rate of digital literacy of Sri Lankans aged 5 to 69 years was about $44.3 \%$ while computer literacy was 30.1\% (Department of Census and Statistics, 2019).

Recent research studies on remote learning during the COVID-19 pandemic also explore learner perceptions on RLA. Top Hat, a private firm dealing with educational technology, has conducted a survey among 3,000 Canadian students about their feelings towards online education during the COVID-19 crisis. According to this survey by Top Hat (2020), over $85 \%$ of the informants preferred learning with their peers as opposed to learning as stand-alone learners. Similarly, $84 \%$ of the informants expressed willingness to return to face-to-face sessions at school. Top Hat (2020) concludes that many students demand an improved online learning experience, more face-to-face sessions with other students as well as improved connections with and support from faculty and administration. Similarly, Allo (2020) investigated students' perceptions of online learning in Indonesia. The qualitative study revealed that online learning has been beneficial to the students during the COVID-19 pandemic. However, students faced difficulties in terms of availability of access to the internet, lack of necessary financial support, and mode of implementation of online learning. Therefore, they preferred online learning conditionally, i.e. if teachers would use freely available online learning services. They mentioned that many of their peers do not have access to the internet. In addition, they expressed that it was necessary to have clearer explanations on learning materials that were provided online by their teachers (Allo, 2020). Likewise, in his study on learner satisfaction on virtual learning, Varma (2021) found that majority of participants were not satisfied with virtual learning activities available to them. However, Gohiya and Gohiya (2020) found that RLA during the pandemic was highly beneficial to students at the university level. In their study, Kohli et al. (2021) discovered that students were dissatisfied with the unexpected disruption to online education. According to Kolhi et al. (2021), the major challenges that the students faced were struggling with online education, difficulty connecting with instructors, lack of motivation, losses, difficulty accessing other learning resources, and an unsafe/inaccessible home environment.

Internet-based RLA has its negative effects as well. This phenomenon would increase the usage of smartphones/tablets among school children thus increasing their screen time. According to Jung et al. (2016), the use of smartphones for long hours could negatively affect children's posture and respiratory system. Kibona and Mgaya (2015) also stated that prolonged use of smartphones negatively affects the academic performance of students.

\section{RESEARCH METHOD}

The current study was conducted as a survey. An online questionnaire with 40 items was administered as a Google Form to collect data from Tamil medium school students from different parts of the country. Initially, a 35-item questionnaire was developed, whereupon the items were revised based on expert review and the number of items was increased to 40 . The questionnaire was divided into segments that focused on students' socio-economic background, their internet accessibility, how they viewed self-learning during the period of physical distancing from school caused by the pandemic, their awareness of the RLA at their disposal, perceptions towards and level of satisfaction with RLA as well as challenges of and problems in engaging in remote learning. The study employed an exponential non-discriminative snowball sampling technique to reach the respondents. Initially, the researchers shared the link to the Google Form with WhatsApp groups of teachers who were known to them. They were asked to share the link with their school students. The survey questionnaire was open for 10 days, and, during this period, it received 613 responses from twenty-two districts of the country. The data were analyzed as mean values, standard deviations, and percentages. 


\section{RESULTS AND DISCUSSION}

\section{The Respondents' Demographic Background}

Out of the 613 respondents representing 22 districts of the country, the majority were from Colombo (17.6\%), Kandy (13.5\%), Batticaloa (13.5\%), Puttalam (12.2\%), and Kalutara (6.7\%). In terms of gender, $57 \%$ were girls and $43 \%$ were boys. The number of respondents in terms of their district and gender is illustrated in Figure 1.

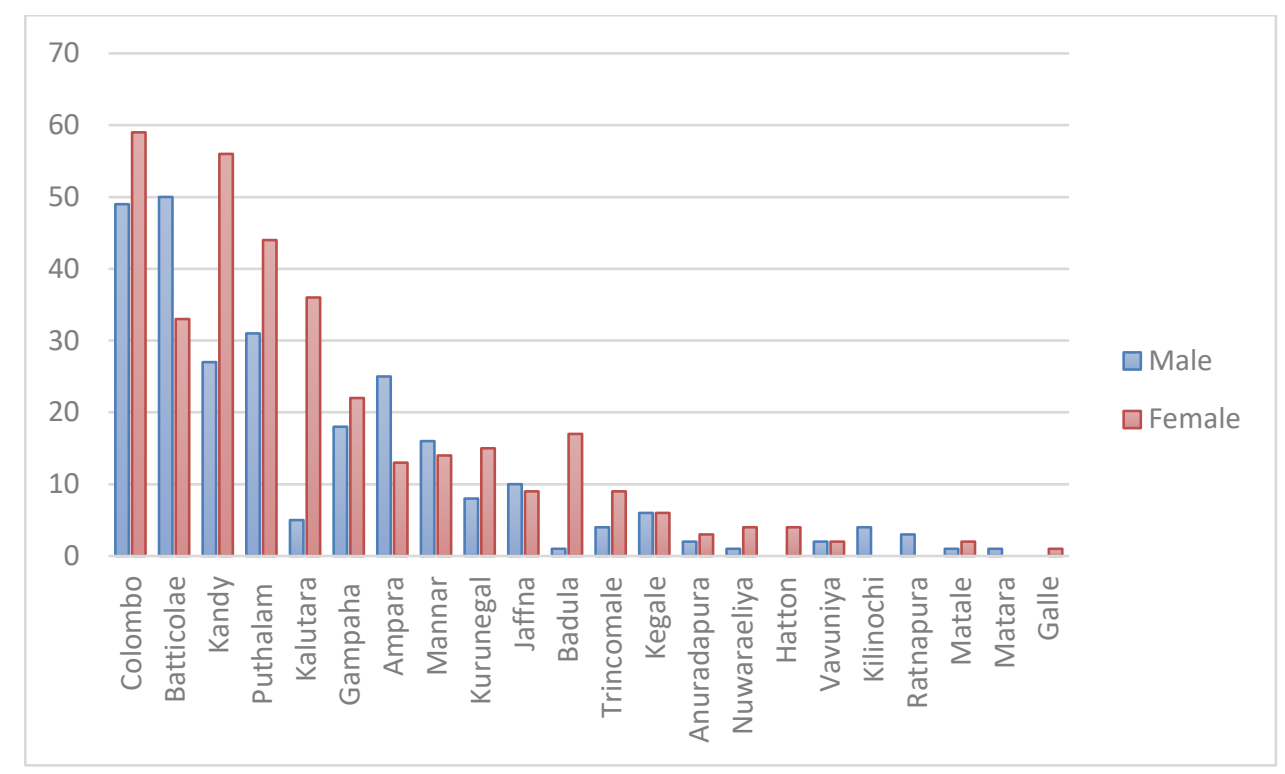

Figure 1. Number of Respondents per District and Gender

In addition, $36 \%$ of the respondents were from G.C.E A/L classes and 34\% were from G.C.E O/L classes. Students at these two grade levels were severely affected by the pandemic situation due to the postponing of their national level examinations. The percentage of respondents in terms of their grade levels at school is shown in Figure 2.

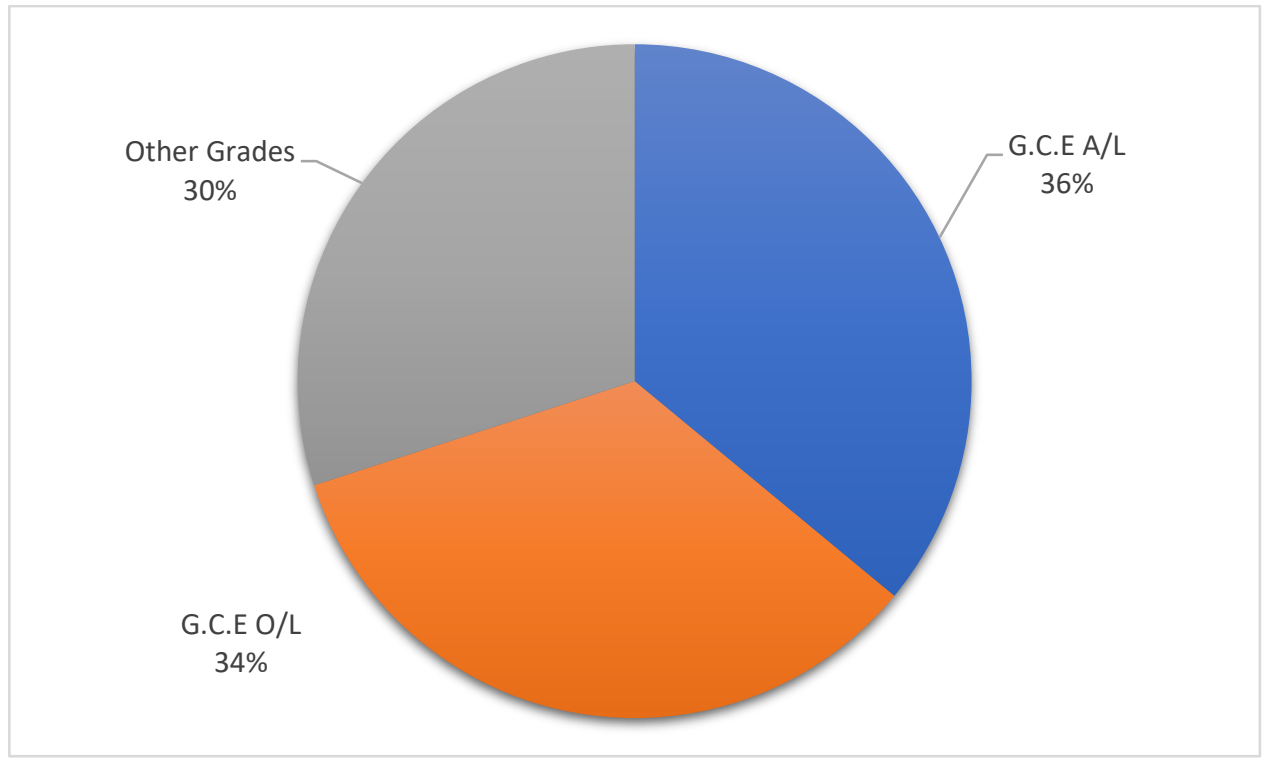

Figure 2. Respondents' Grade Levels at School (\%)

\section{Respondents' Awareness about RLA}


School students in Sri Lanka were affected by the sudden closure of schools followed by the lockdown due to the pandemic situation. In particular, students who were preparing for the G.C.E. O/L and G.C.E. A/L Examinations were severely affected. Realizing this, the Ministry of Education along with the National Institute of Education launched an educational television program called Gurugedera to facilitate school students to continue their studies at home. In addition, teachers also voluntarily came out with alternative strategies to reach out to their students at home. They started using social media especially WhatsApp and basic video conferencing apps which are available free of charge, to teach their students. Teachers sent educational content and activities to the WhatsApp groups and taught via video conferencing apps. In this context, it is very important to know to what extent students are aware of the availability of these RLA. The majority of the respondents $(92 \%)$ were aware of various RLA available for their benefit during the closure of schools in response to the COVID-19 pandemic. They had been made aware of RLA through social media $(36.9 \%)$ as well as by teachers $(23.7 \%)$, peers $(22.6 \%)$, and parents $(16.8 \%)$. Therefore, they could access RLA available through a variety of sources. These sources of RLA included television (31\%), the radio (28\%), Zoom/Google Meet sessions $(57 \%)$, and other social media (44\%). Figure 3 shows the means through which students got to know about the RLA available to them.

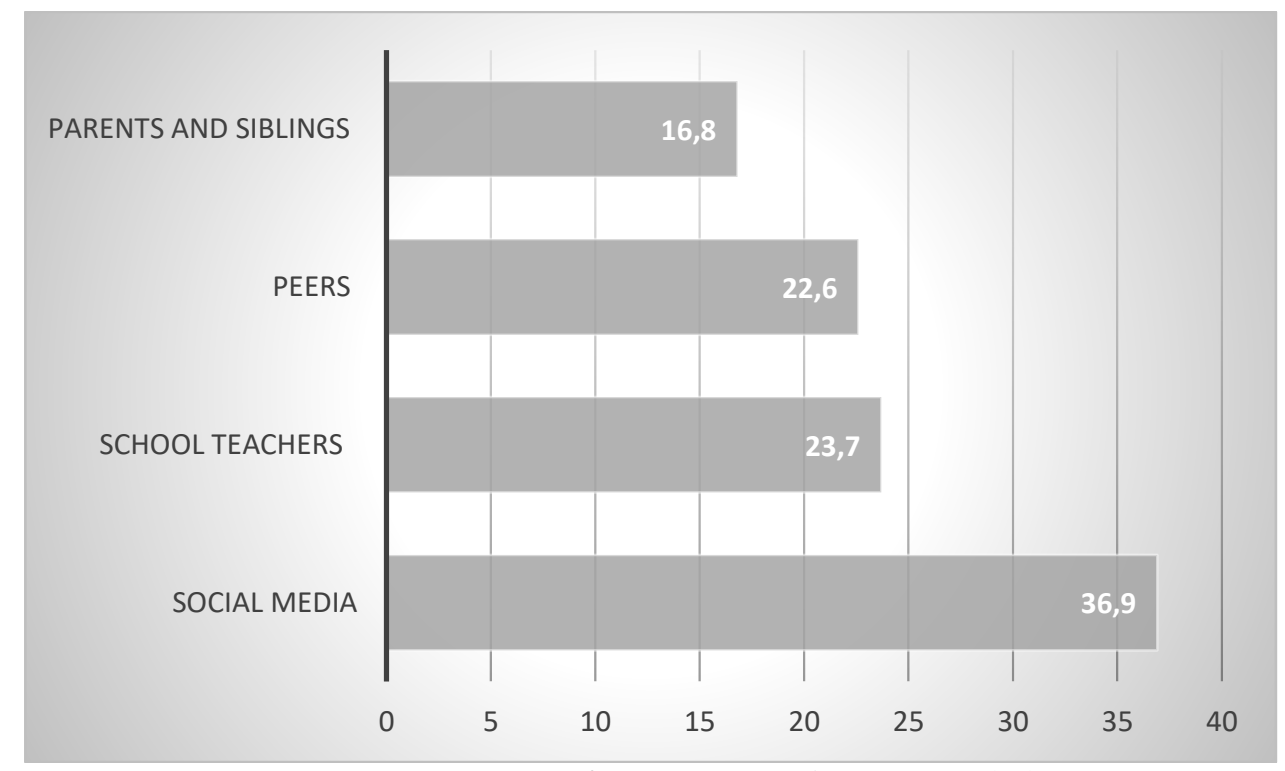

Figure 3. Sources of awareness about RLA (\%)

According to Figure 3, social media had a considerable impact on making awareness of RLA. It was mentioned by some respondents that some teachers invited students from other schools to their classes via social media, especially through Facebook. It was also noted that parents and siblings were also concerned about the availability of RLA and made their children aware of those which were accessible to them. Likewise, numerous learning materials and activities in the form of pdf documents, presentations, Google Forms, and short videos were circulated through social media such as WhatsApp and Facebook. The majority of the respondents (67.5\%) stated that they received learning activities from teachers. Teachers conducted their teaching-learning activities using technology in the daytime. A small number of respondents $(13.3 \%)$ mentioned they watched the Gurugedara TV program which was telecast during the daytime. However, it was noted that since both online classes conducted by teachers and the educational television programs took place at the same time, a smaller number of respondents engaged with the latter. 


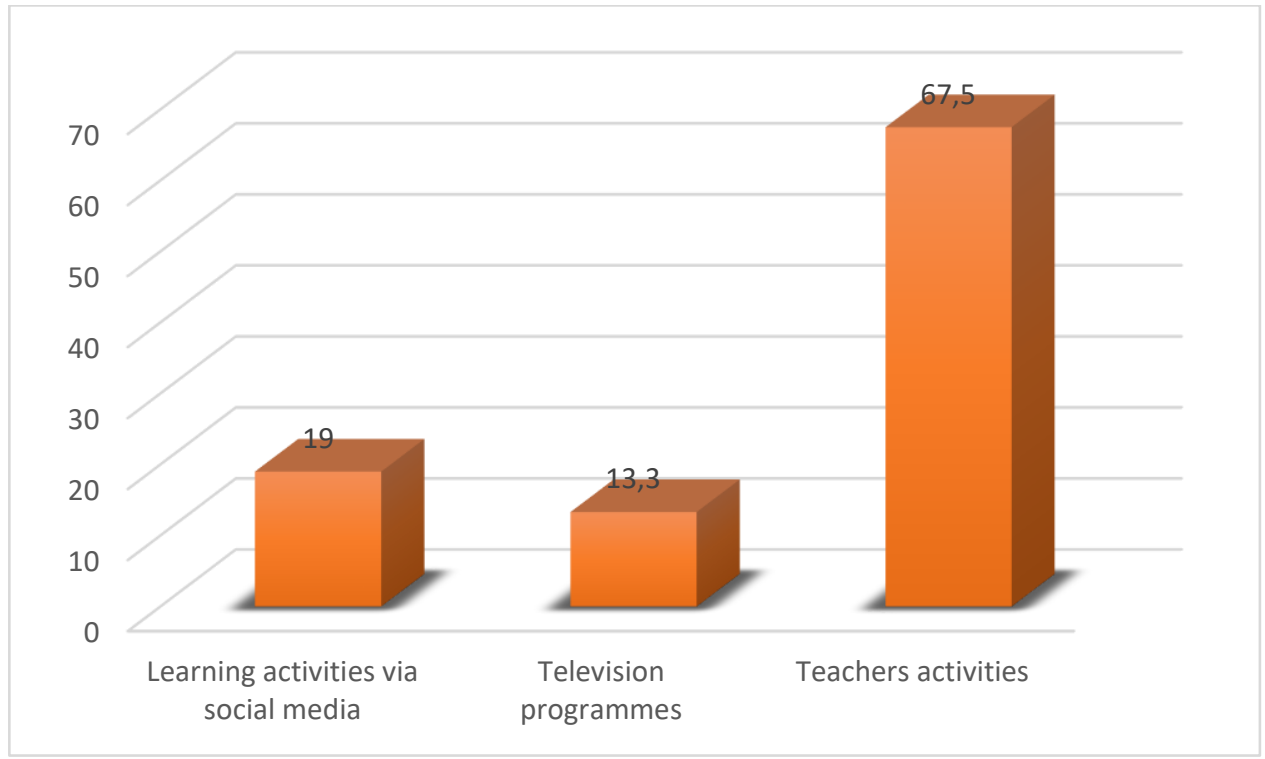

Figure 4. Students' Engagement with RLA

\section{Facilities Available for Students to Engage in Remote Learning}

Figure 5 provides an overall picture of the basic facilities available to the respondents in terms of house ownership and internet facilities available at home as well as expenditure on accessing the internet. Analysis of data related to the nature of respondents' current residence revealed that $82.1 \%$ were living in their own house. All the respondents have mentioned that they have electricity at their abode. In terms of internet services used at home, $16.8 \%$ have fixed lines, $62.6 \%$ use broadband services from mobile service providers and the other respondents $(20.6 \%)$ don't have any internet access. It is interesting to note that $69.5 \%$ of the respondents access internet using pre-paid services. In addition, majority of the respondents $(34.7 \%)$ mentioned that their expenditure on internet access was Sri Lankan Rupees (SLR) 500.00-1,000.00 per month whilst $21.4 \%$ spent more than SLR 1,500.00 per month.

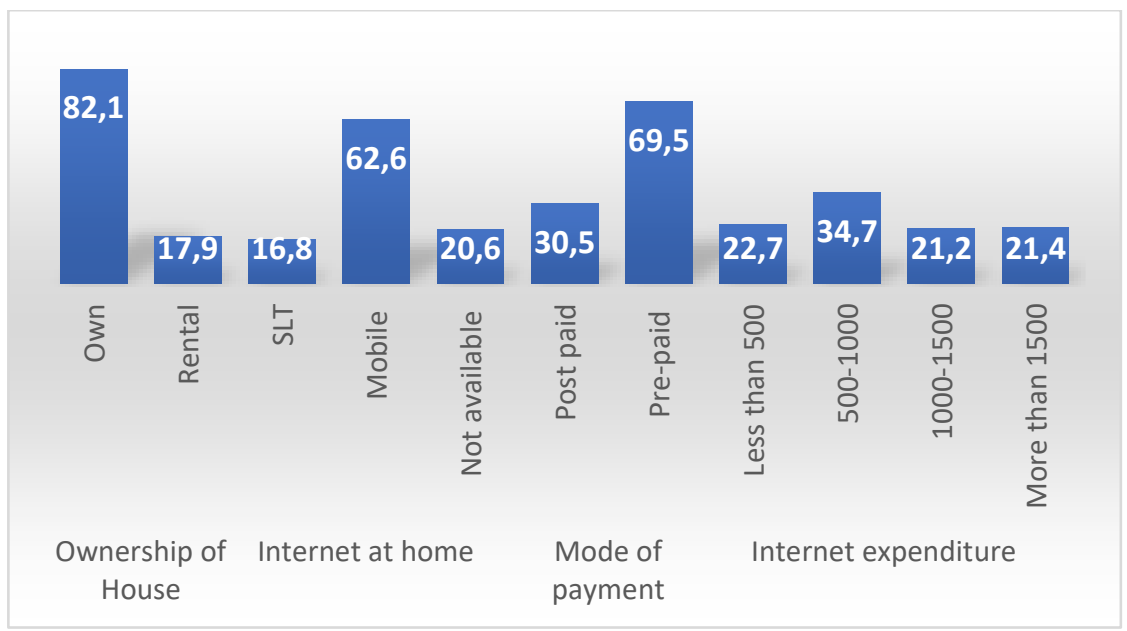

Figure 5. House ownership, Availability of Internet Facilities and Expenditure on Internet

Concerning facilities available for students to engage in remote learning, this study also focused on the availability of devices for learning purposes. Figure 6 shows the devices available for learning and occupations of the respondents' parents. Sixty-one-point nine percent $(61.9 \%)$ of the respondents used smartphones and around $18.2 \%$ had computers or laptops at home. Tablets and TV were available to $6 \%$, and $5.7 \%$ of the respondents respectively. It is noteworthy that $7.9 \%$ of the respondents did not have any devices to access RLA. This resonates with Varma's finding (2021) that majority of the respondents (94\%) used smartphones for accessing virtual learning 
during the global pandemic. The respondents of this study were asked about the occupational status of the main income earner of the family; it was revealed that $30 \%$ of the parents were selfemployed or engaged in their own business, $25.8 \%$ were government sector employees, and $25.9 \%$ were daily paid laborers. It is also noteworthy that $7.1 \%$ of the parents were unemployed.

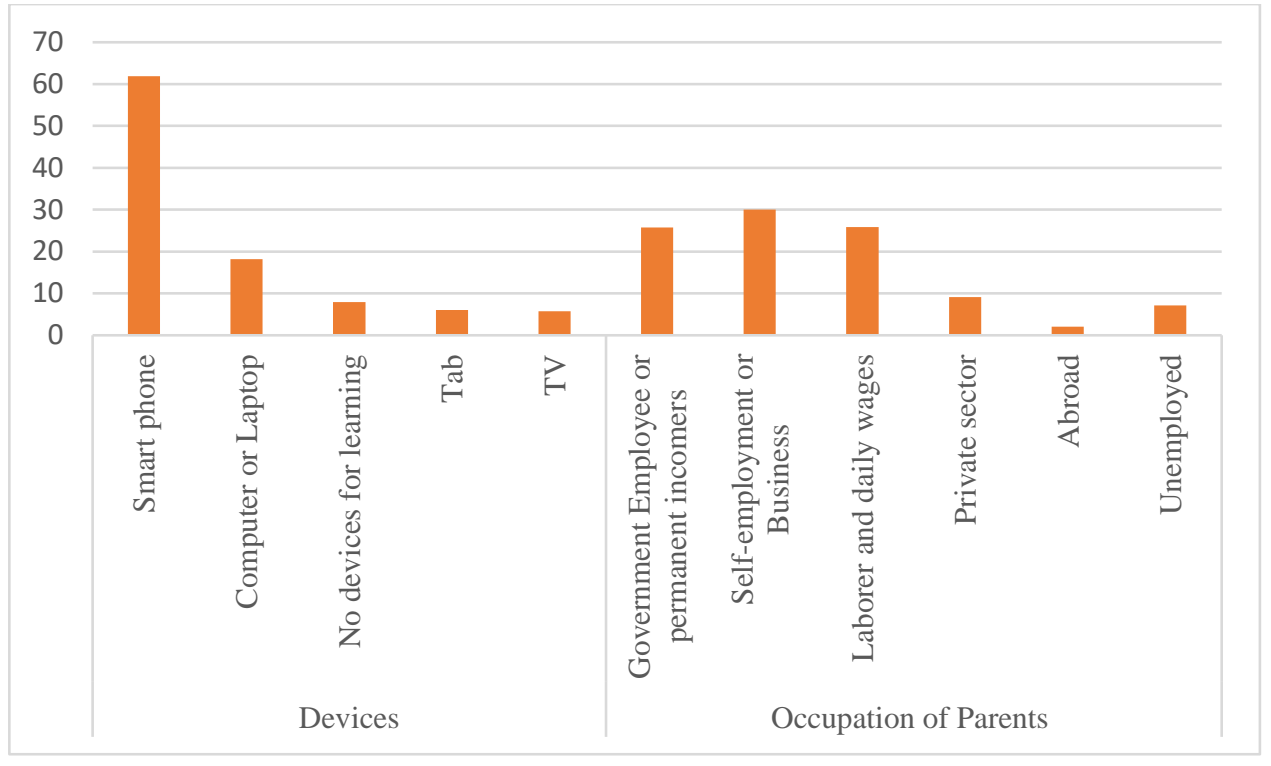

Figure 6. Devices available for learning and occupation of parents

\section{Respondents' perceptions of RLA}

The respondents' perceptions on RLA about self-learning, usefulness of remote learning, satisfaction of engaging in RLA and TV programs, and challenges they faced in engaging in RLA were assessed using five-point Likert scale items with responses ranging from "totally disagree" (1) to "totally agree" (5).

Table 1. Students' Perception towards RLA

\begin{tabular}{llll}
\hline Aspects of Perception & $\mathrm{N}$ & Mean & Std. Deviation \\
\hline Attitudes towards Self-learning & 613 & 3.5021 & .81622 \\
Usefulness of remote learning & 613 & 3.5672 & 1.02194 \\
Satisfaction with RLA & 613 & 3.4214 & 1.07128 \\
Challenges & 613 & 3.5465 & .98567 \\
Satisfaction with educational TV programs & 613 & 3.3442 & .92917 \\
\hline
\end{tabular}

Table 1 shows the mean and standard deviation of the students' perceptions towards RLA which were at their disposal during the closure of schools in response to the COVID-19 pandemic. The mean values in all the five aspects-attitudes towards self-learning $(\mathrm{M}=3.50, \mathrm{SD}=0.81)$, usefulness of RLA $(M=3.56, S D=1.02)$ satisfaction with RLA $(M=3.42, S D=1.07)$, satisfaction with educational TV programmes $(\mathrm{M}=3.34, \mathrm{SD}=0.92)$ and challenges $(\mathrm{M}=3.54, \mathrm{SD}=.98)$ - were almost the same. This indicates that the respondents were uncertain about self-learning and RLA assigned by teachers. Particularly, the students were not satisfied with educational TV programs.

Table 2 shows students' attitudes towards self-learning during the lockdown of the country. Around $60.8 \%$ of the respondents realized that they had to continue with self-learning to continue their education. The majority of the respondents $(64 \%)$ were confident that they could continue self-learning with success during the period of physical distancing followed by the outbreak of the COVID-19 pandemic. In addition, nearly 70\% of the respondents accepted that they had a home environment conducive for self-learning.

However, over half of the respondents of this study (53\%) were concerned that they were not able to discuss subject matter with their peers. This indicates that they would prefer to go back to 
face to face sessions at school under the new normal conditions. This was confirmed by a considerable number of the respondents making statements such as "It is more difficult to understand the lessons now than when learning in the classroom," and "there is no space in online learning either to clarify our doubts or to discuss the lesson with our teachers and peers." Similar findings were made by Bestiantono et al. (2020) in that students in junior high schools in Indonesia expressed an absence of eye-to-eye connection with the educator and non-attendance of conventional homeroom socialization as issues they faced when engaging in online learning during the COVID-19 pandemic.

Table 2. Respondents' Attitudes towards Self-Learning at Home (\%)

\begin{tabular}{llllll}
\hline Item & $\begin{array}{l}\text { Totally } \\
\text { disagree }\end{array}$ & Disagree & Neutral & Agree & $\begin{array}{l}\text { Totally } \\
\text { Agree }\end{array}$ \\
\hline $\begin{array}{l}\text { I get enough time to do self-learning at home } \\
\begin{array}{l}\text { I feel I need to learn my lessons on my own } \\
\text { at home }\end{array}\end{array}$ & 11.0 & 6.4 & 20.9 & 34.4 & 30.3 \\
$\begin{array}{l}\text { I feel I have a good home environment for } \\
\text { self-learning }\end{array}$ & 9.1 & 7.8 & 17.6 & 30.0 & 30.8 \\
$\begin{array}{l}\text { After self-learning, I am unable to discuss the } \\
\text { things learned with my peers }\end{array}$ & 20.9 & 12.9 & 13.2 & 24.0 & 29.0 \\
$\begin{array}{l}\text { I do not have time to revise my lessons at } \\
\text { home }\end{array}$ & 14.0 & 19.7 & 24.1 & 25.0 & 17.1 \\
\hline
\end{tabular}

Table 3 shows respondents' perceptions about the usefulness of RLA. The majority of them (60\%) stated that they benefited from various RLA. However, only half of the respondents agreed that they could understand the online lessons. It was noted that, during the lockdown period, many teachers prepared quizzes using Google Forms and assessed students' knowledge of subject content. Nearly $66 \%$ of the respondents agreed that they benefitted from such online tests. These findings are comparable to those of Gohiya and Gohiya (2020) on student perceptions of the benefits of RLA.

Table 3. Students' perceptions on the usefulness of RLA (\%)

\begin{tabular}{|c|c|c|c|c|c|}
\hline & $\begin{array}{l}\text { Totally } \\
\text { disagree }\end{array}$ & Disagree & Neutral & Agree & $\begin{array}{l}\text { Totally } \\
\text { Agree }\end{array}$ \\
\hline $\begin{array}{l}\text { I get more benefits through remote learning } \\
\text { activities conducted by teachers }\end{array}$ & 8.6 & 9.5 & 21.5 & 36.2 & 24.1 \\
\hline $\begin{array}{l}\text { Remote learning activities help me to understand } \\
\text { the lessons easily }\end{array}$ & 9.5 & 13.2 & 25.0 & 34.6 & 17.8 \\
\hline I get more benefits through online tests & 8.3 & 6.9 & 17.5 & 36.9 & 30.5 \\
\hline
\end{tabular}

\section{Challenges and Issues in Remote Learning}

Some of the close-ended and open-ended items in the survey focused on the challenges and issues faced by the respondents when engaged in remote learning. One of the challenges faced by the respondents was affordability, which was a major concern in accessing RLA. Nearly half of the respondents stated that they could not afford the expenditure on internet access to engage in RLA. Statements such as "We are having a hard time buying a net card, "More money is needed for data cards", "Online data costs are not affordable," and "A large amount of data is spent" shed light on different nuances of the difficulties they faced during the period of lockdown and physical distancing. These findings resonate with those of Simamora (2020) who reports on challenges faced by Indonesian students at the tertiary level due to the sudden transition from on-campus to online learning. In addition, majority of the respondents mentioned issues related to the availability of internet coverage in their home area. These issues were voiced through 
statements such as "I don't have enough coverage at my home, therefore, I have to go out to get internet," "Internet is very slow thus I could not hear or watch what my teacher taught online" and "Data is not enough to engage with online classes in the daytime." Parallel to this, the Ministry of Education also reported that over 700,000 students were unable to access online education provided by various institutions (Hapuarachchi, 2021) due to poor internet coverage in village areas. Aljazeera (2021) also reported that many students from villages walked two or more miles and climbed trees to access internet signals. Zainudeen and Amarasinghe (2020), and Allo (2020) also report on similar findings.

Table 4. Respondents' Screen Time per Day

\begin{tabular}{ll}
\hline Screen Hours & \% of Respondents \\
\hline less than 1 hour & 20.4 \\
1-5 hours per day & 62.5 \\
5-8 hours per day & 11.9 \\
More than 8 hours & 5.2 \\
\hline
\end{tabular}

Table 4 shows the respondents' daily screen time in terms of the number of hours. Majority of them $(62.5 \%)$ spent $1-5$ hours per day engaging in RLA while $11.9 \%$ spent $5-8$ hours on RLA per day. Spending 1-5 hours per day on remote learning would consume much data, which was difficult to be afforded by their families. These findings also have serious implications about effects on children's sleep, attention, and energy levels due to prolonged screen time. Studies have pointed to the fact that children who spend a considerable amount of time on screens were more likely to develop eye problems, weight problems, and language difficulties. They are also more prone to exhibit a variety of other physical and mental health problems (Hulick, 2021). It is noteworthy that school students' prolonged use of smartphones would have serious repercussions on their health and academic performance in the long run, as also mentioned by Jung et al., (2016) and Kibona and Mgaya (2015). In addition, majority of the respondents (60\%) stated that they received an excess of exercises as RLA, which led to high expenditure on printing. Likewise, about $42 \%$ of the respondents felt that the educational programs on television were broadcast during inappropriate times of the day.

Open-ended items on the survey also revealed many other problems and challenges in RLA. Some of the respondents made statements such as "Multiple zoom meetings are held for several subjects simultaneously," and "Only one device is available at home to share with siblings who are all in school age." One female student mentioned, "Boys are getting phone numbers while participating in online learning and they gave missed calls and it's a lot of disturbing." Such issues have also been reported in local media widely. Therefore, parents should closely monitor and guide their children when they are engaged in RLA.

\section{CONCLUSIONS}

Due to the closure of Sri Lankan schools in response to the COVID-19 pandemic, school children have lost the learning opportunities which they previously received from the schools. Especially, students in G.C.E O/L and A/L classes were deeply concerned about the situation as they were preparing for important examinations which are normally considered to be milestones in their school career. However, a variety of internet-based and non-internet-based learning activities have been made available across the country both by governmental and non-governmental entities to facilitate the continuation of their learning. The present study found that majority of respondents were aware of the various RLA available to them, and they were informed of them by their school teachers, peers, and social media. The majority of the respondents believed that they had plenty of time for self-learning at home while they were maintaining physical distancing in the safety of their home in response to COVID-19. Generally, they were satisfied with the RLA that they participated in. About $40 \%$ of them engaged in learning through educational programs broadcast via television and radio. About $91.7 \%$ of respondents were using smartphones to access 
RLA which were carried out through Zoom/Microsoft meetings, webinars, and some live social media programs conducted by various interest groups. However, it was found that half of the respondents could not afford the cost of data to engage in remote learning.

\section{RECOMMENDATIONS}

Based on the findings of this study, it is recommended that to ensure equality of access to education, school students should be provided with devices free of charge to access RLA, and all internet-based educational programs should be made available free of charge. In addition, data to access RLA should be made available to students at a concessionary price without reducing the speed of internet services and that island-wide network coverage be provided. Educational programs which are broadcast on television should be improved in quality; this could be realized by developing suitable protocols to ensure their quality. This would particularly be beneficial for children from lower-income families to access remote learning. Moreover, it is recommended that parents be made aware of how to facilitate their children's engagement in remote learning. On principle, the development of students' competencies related to 'learning to learn has been given foremost attention in the Sri Lankan curriculum since 1997 (Nawastheen et al., 2020). Therefore, the practice of facilitating students to prepare for self-learning at home is an important aspect that needs to be focused on at the moment. Demonstrating how to engage in meaningful self-learning at home via mass media and social media would be highly beneficial to students. At the same time, students, teachers, and parents should be made aware of the negative impact of prolonged usage of smartphones and tablets on children's academic achievement and health.

As the present study focused on a sample of Tamil medium students, it is recommended that future studies should focus on students studying in other languages (i.e. Sinhala and English) to gain deeper insights on school students' experiences with RLA in the Sri Lankan context. Further, studies focusing on the experiences of teachers and parents on school children's remote learning are also considered to be beneficial.

\section{ACKNOWLEDGEMENTS}

We would like to thank Mr. M.N. Ikram who helped us in the process of data collection.

\section{REFERENCES}

Aljazeera. (2021, July 13). Sri Lankan children make a dangerous climb for online school. Aljazeera. https://www.aljazeera.com/gallery/2021/7/13/sri-lankan-children-make-a-dangerousclimb-for-online-school

Allo, M. D. G. (2020). Is the online learning good in the midst of COVID-19 pandemic? The case of EFL learners. Jurnal Sinestesia, 10(1), 1-10.

Bestiantono, D. S., Agustina, P. Z. R., \& Cheng, T. H. (2020). How students' perspectives about online learning amid the COVID-19 pandemic? Studies in Learning and Teaching, 1(3), 133-139. https:// doi.org/10.46627/silet.v1i3.46

Department of Census and Statistics. (2019, January - December). Computer Literacy Statistics 2019 (Annual). Poluwa Road, Battaraulla, Sri Lanka. http://www.statistics.gov.lk/Resource/en/ComputerLiteracy/Bulletins/AnnualBuletinCo mputerLiteracy-2019

Kibona, L., \& Mgaya, G. (2015). Smartphones' effects on academic performance of higher learning students: a case of Ruaha Catholic University - Iringa, Tanzania. Tanzania Journal of Multidisciplinary Engineering Science and Technology, 2(4), 777-784.

Kohli, H., Donna W., \& Amarpreet K. (2021). Impact of online education on student learning during the pandemic. Studies in Learning and Teaching, 2(2), 1-11. https:// doi.org/10.46627/ silet.v2i2.65 
Gohiya, P., \& Gohiya, A. (2020). E-learning during COVID-19 Pandemic. Research Square. https://doi.org/10.21203/rs.3.rs-29575/v1

Hapuarachchi, P. (2021, July 30). Significant rise in Cyberbullying cases in Sri Lanka: SLCERT. News 1st. https://www.newsfirst.lk/2021/07/30/significant-rise-in-cyberbullying-cases-insri-lanka-slcert/

Hulick, K. (2021, September 11). Healthy screen time is one challenge of distance learning. Science News for Students. https://www.sciencenewsforstudents.org/article/healthy-screen-timeis-one-challenge-of-distance-learning

Jung, S., Lee, N., Kang, K., Kim, K., \& Lee, D. (2016). The effect of smartphone usage time on posture and respiratory function. Journal of Physical Therapy Science, 28(1), 186-189. https://doi.org/10.1589/jpts.28.186

Nawastheen, F. M., Jazeel, M. I. M., Sifani, K. R., \& Ponniah, K. (2020). Teachers' roles in developing self-regulated learning strategies among students of puttalam division in Sri Lanka. Journal of Critical Reviews, 7(19), 5076-5084.

Ranawana, A. (2020, May 12). Internet-based education won't work now for Sri Lankan children - EFSL. Economynext. https://economynext.com/internet-based-education-wont-work-nowfor-sri-lankan-children-efsl-69890/

Sears, D. (2020, April 30). What is the difference between remote and distance learning?. Bromcom https:/ / bromcom.medium.com/ what-is-the-difference-betweenremote-and-distancelearning-11552f45d998

Simamora, R. M. (2020). The challenges of online learning during the COVID-19 pandemic: An essay analysis of performing arts education students. Studies in Learning and Teaching, 1(2), 86 103. https:// doi.org/10.46627/silet.v1i2.38

Top Hat. (2020, May 01). Adrift in a pandemic: Survey of 3,089 students finds uncertainty about returning to college. Top Hat. https://tophat.com/press-releases/adrift-in-a-pandemicsurvey/

UNESCO. (2020). Global Education Coalition, message from Audrey Azoulay. UNESCO DirectorGeneral. https://www.youtube.com/watch?v=St_BQRSXmew\&t=37s

Varma, C. (2021). A Study of virtual learning experience of student teachers: Learner's satisfaction and learning needs. International Journal of Research and Scientific Innovation, 8(8), 25-29.

Viner, R. M., Russell, S. J., Croker, H., Packer, J., Ward, J., Stansfield, C., Mytton, O., Bonell, C., \& Booy, R. (2020). School closure and management practices during coronavirus outbreaks including COVID-19: A rapid systematic review. The Lancet Child E Adolescent Health, 4(5), 397-404.

World Bank Group. (2020). Remote learning during the global school lockdown: Multi-country lessons. International Bank for Reconstruction and Development. https:// documents1.worldbank.org/curated/en/668741627975171644/pdf/RemoteLearning-During-the-Global-School-Lockdown-Multi-Country-Lessons.pdf

Zainudeen. A., \& Amarasinghe, A. (2020, May 16). E-learning opportunities in the Asian Global South. Colombo, Sri Lanka. https://lirneasia.net/wp-content/uploads/2020/05/E-learningopportunities-in-the-Asian-Global-south.pdf 
Students' Perceptions on Participating in Remote Learning Activities in the time of Covid-19 Pandemic https://doi.org/10.46627/silet.v2i3.81

Author (s):

* Fareed Mohamed Nawastheen (Corresponding Author)

Department of Secondary \& Tertiary Education,

Faculty of Education,

The Open University of Sri Lanka, Sri Lanka

Email: fmnaw@ou.ac.lk

S.A.S. Kaushalya Perera

Department of Secondary \& Tertiary Education,

Faculty of Education,

The Open University of Sri Lanka, Sri Lanka

Email: saper@ou.ac.lk 